Supplement of Saf. Nucl. Waste Disposal, 1, 187-188, 2021

https://doi.org/10.5194/sand-1-187-2021-supplement

(C) Author(s) 2021. CC BY 4.0 License.

(c) (i)

Supplement of

\title{
Uncertainties in geomechanical models - exhaustive vs. feasible approach
}

Moritz Ziegler and Oliver Heidbach

Correspondence to: Moritz Ziegler (moritz.ziegler@gfz-potsdam.de)

The copyright of individual parts of the supplement might differ from the article licence. 


\section{GF Z Uncertainties in geomechanical models}

Exhaustive vs. feasible approach

\section{Abstract}

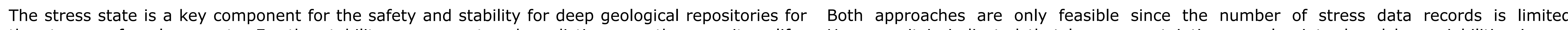

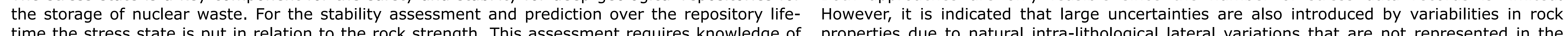

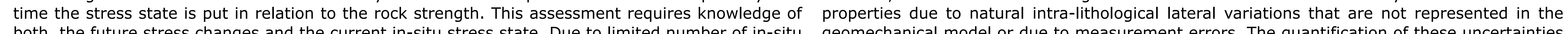

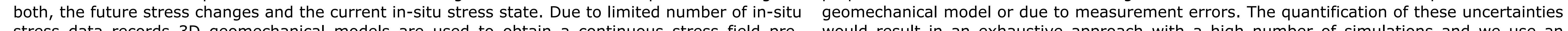

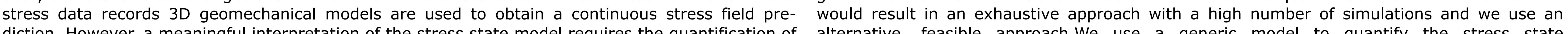

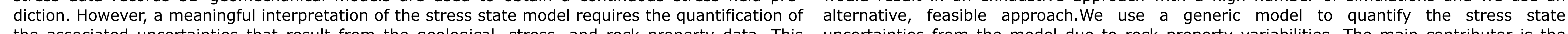

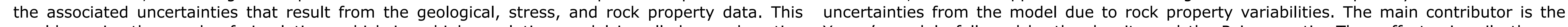

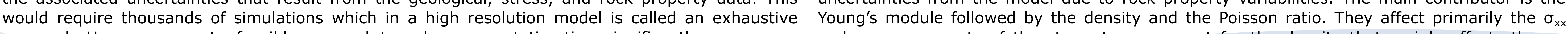
would require the unds of simusions whe The exhaustive approach quantifies uncertainties that are due to variabilities in stress data records. Therefore, all available data records within a model volume are used individually in separate simulations. Due to the inherent variability in available data, each simulation presents one of many individual probability density function for each component of the stress tensor represented by an average value and a standard deviation. If a weighting of the data records can be performed, the standard deviation usually can be reduced and the significance of the model result is improved. Alternatively, a range of different stress states supported by the data can be provided with the benefit that no outliers are disregarded, but this comes at the cost of a loss in precision.

\section{Best-fit approach}

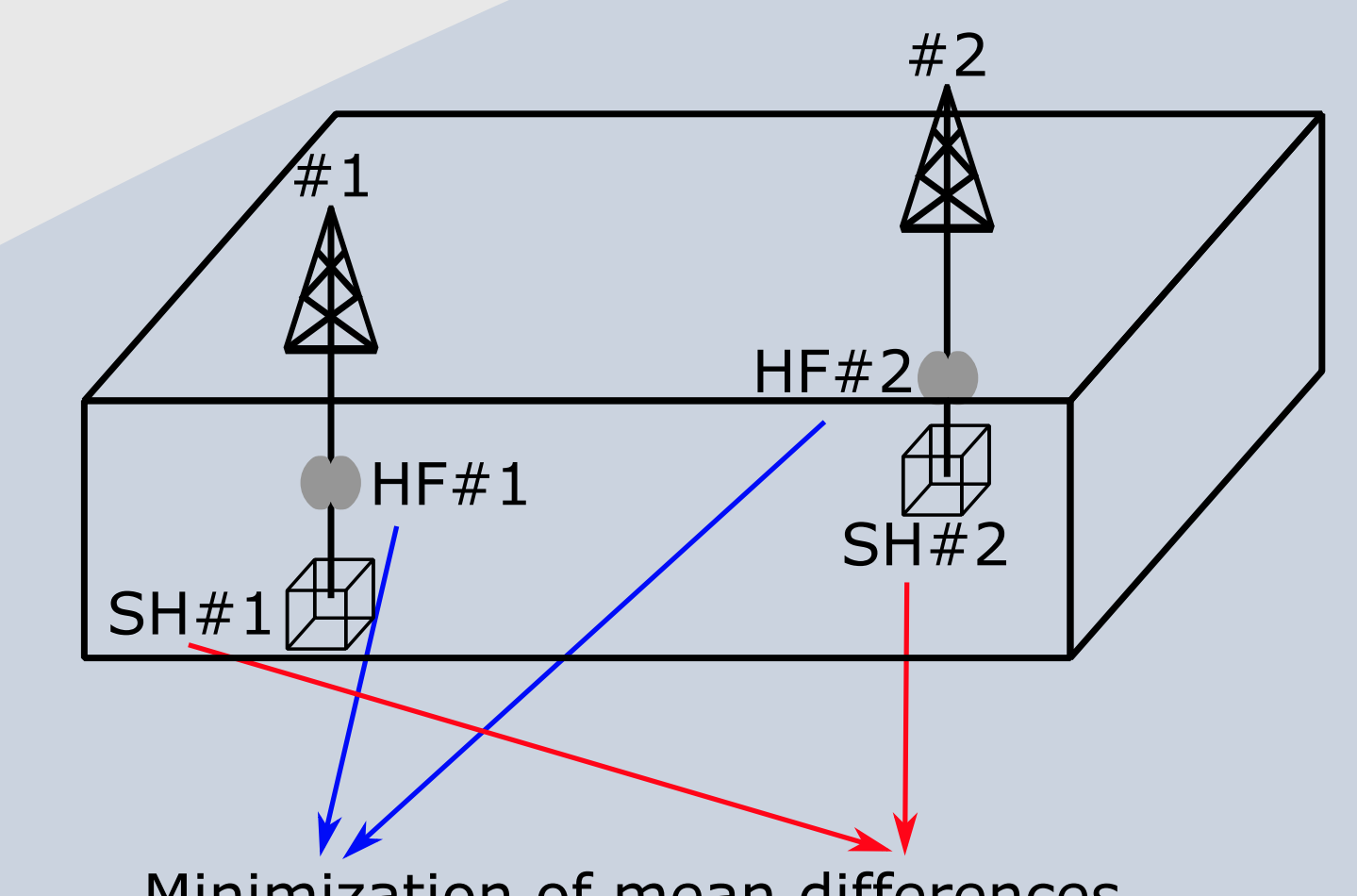

Minimization of mean differences between model and observation: the best-fit approach

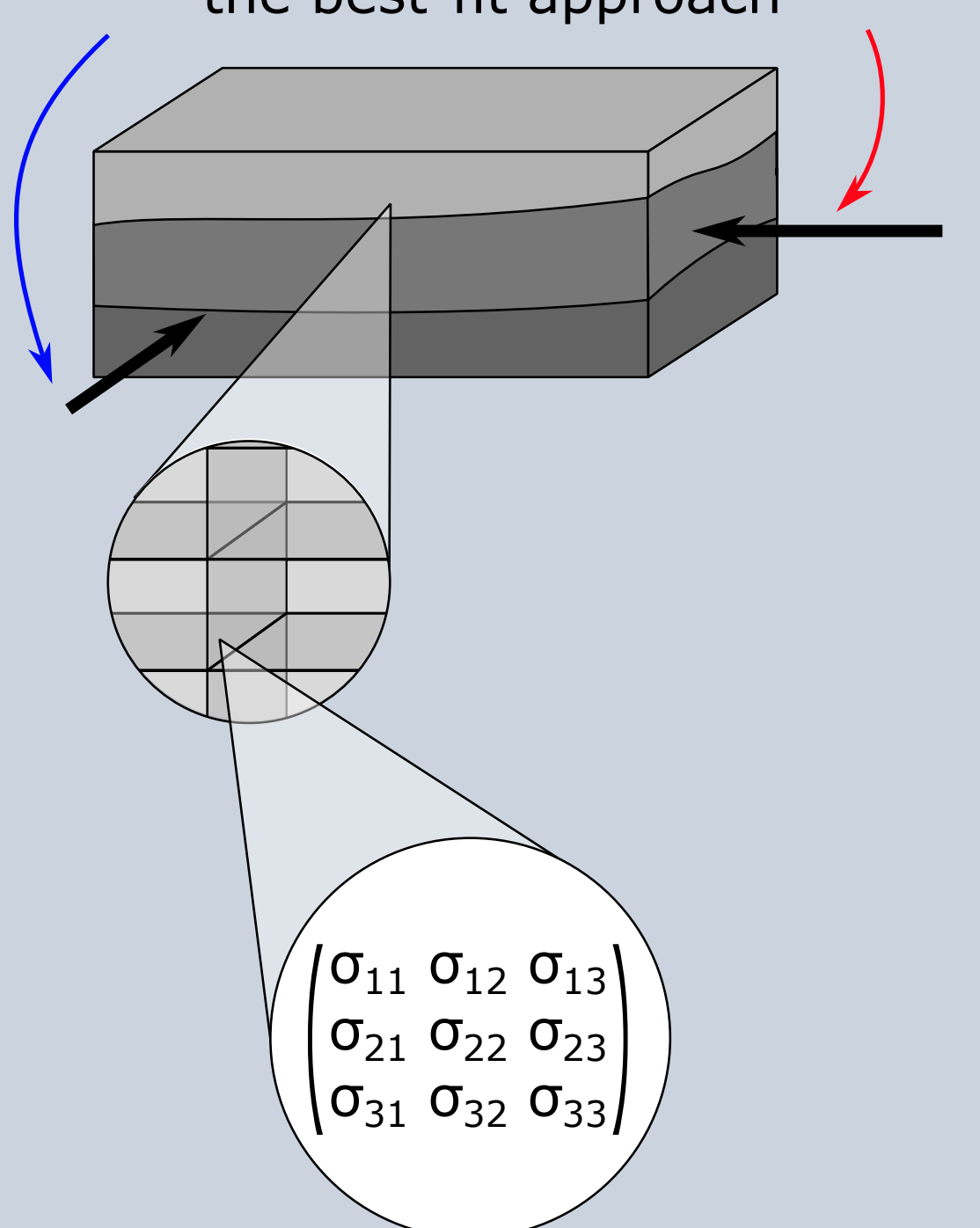

Quantification of uncertainties

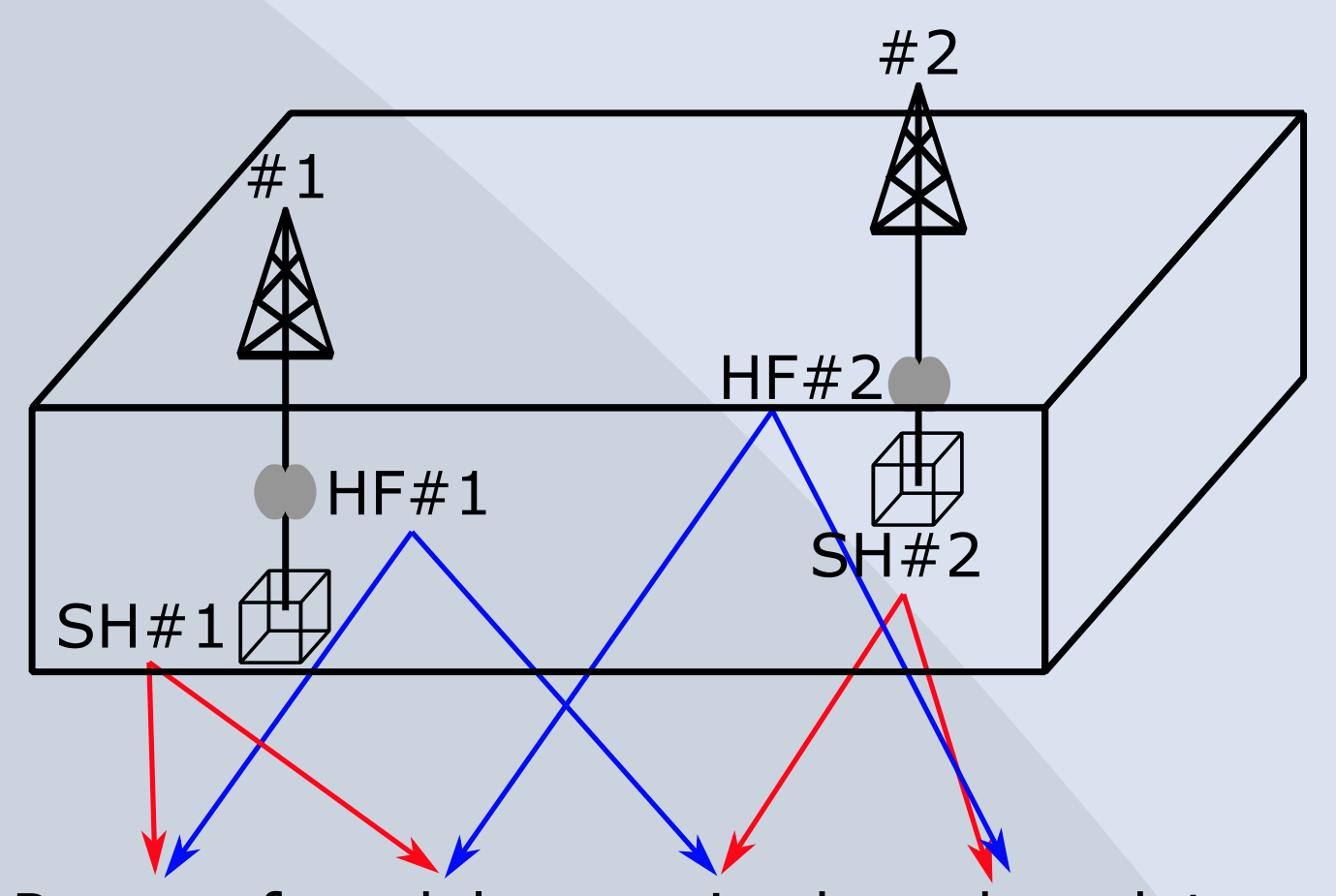

Range of model scenarios based on data pairs. For beach data pair a matching set of boundary conditions is provided.

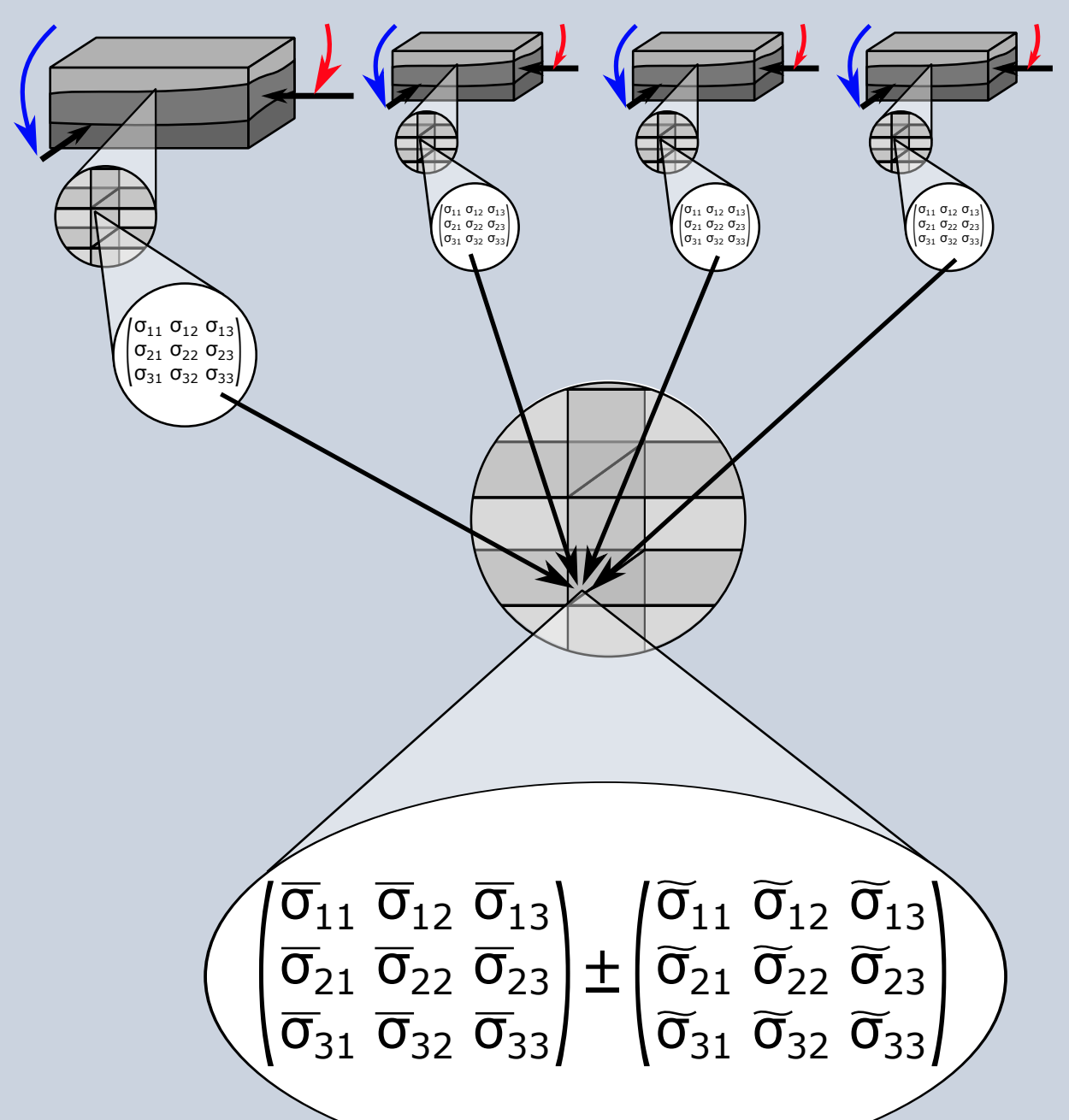
and $\sigma_{y y}$ components of the stress tensor except for the density that mainly affects the $\sigma_{z z}$ component. Furthermore, a relative influence of the stress magnitudes, the tectonic stress regime, and the absolute magnitude of rock properties are observed. We propose to use this information in a post-computation assignment of uncertainties to the individual components of the stress tensor. A range of lookup tables need to be generated that compile information on the effect of different variabilities in the rock properties on the components of the stress tensor in different tectonic settings. This allows to feasibly quantifying uncertainties in a geomechanical model and to increases the significance of the model results significantly.

Reduction of uncertainties

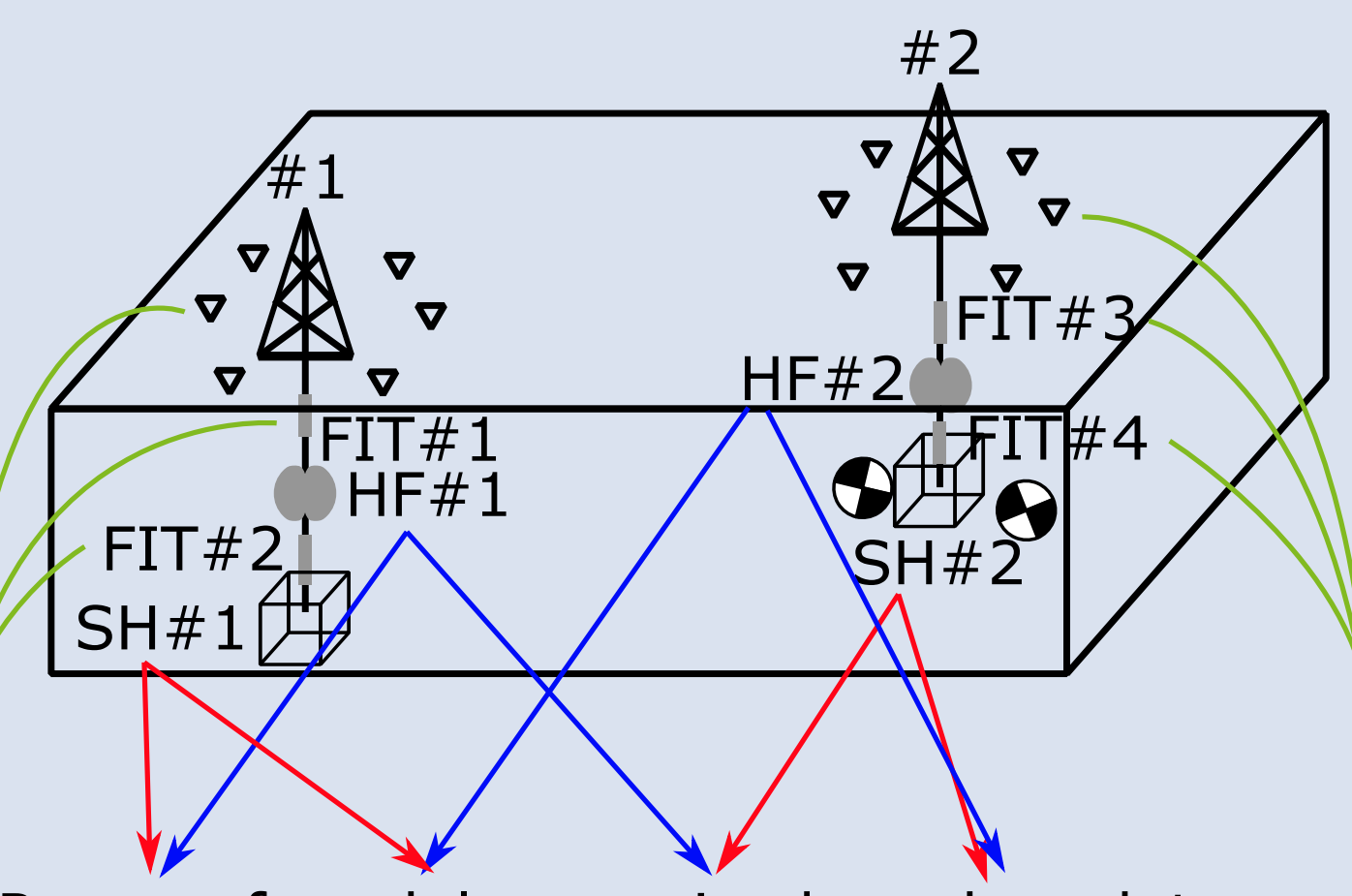

Range of model scenarios based on data pairs. For beach data pair a matching set of boundary conditions is provided.

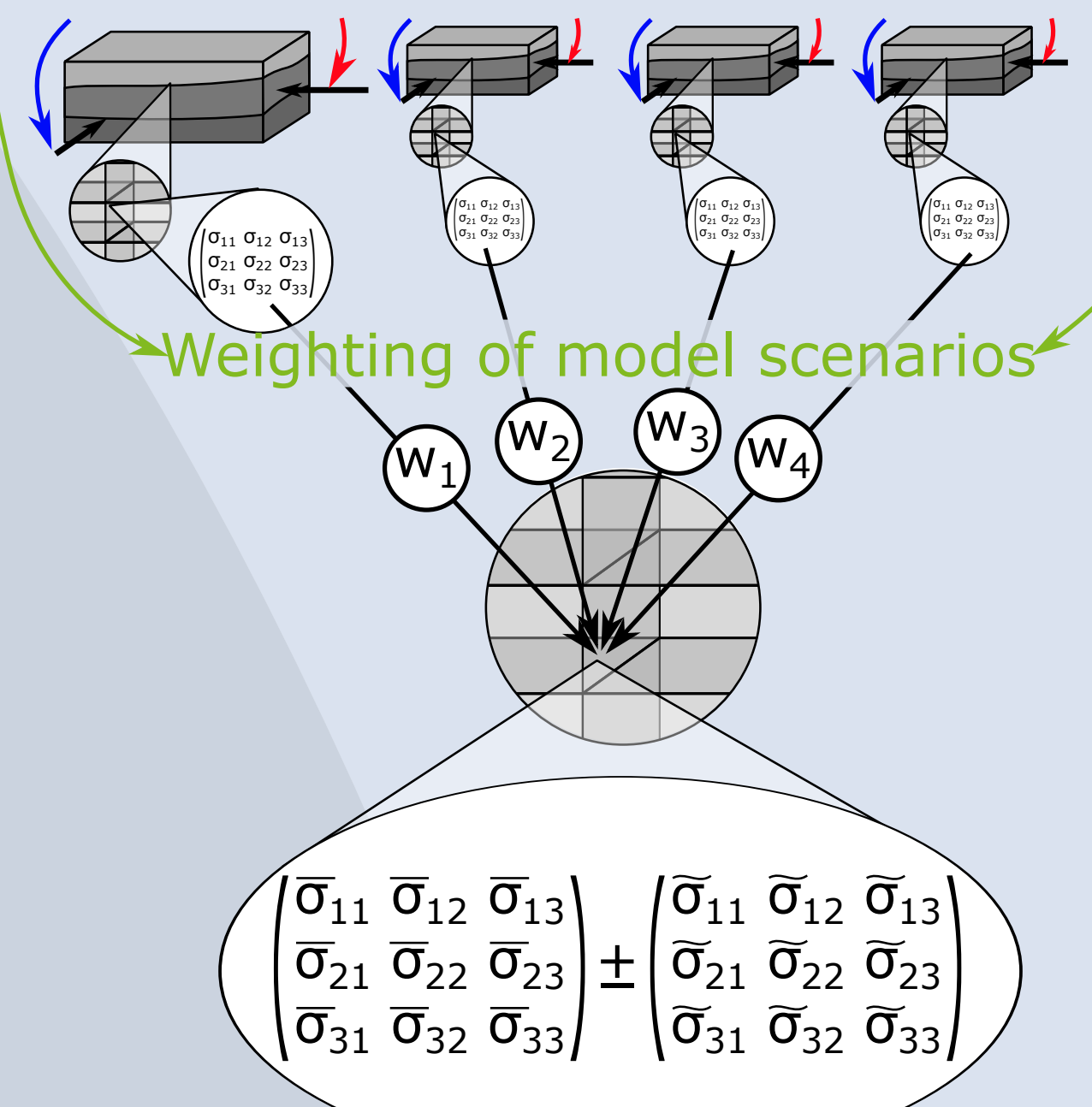

Synopsis in German einfach Für interessierte Laien

Mechanische Gebirgsspannungen sind die Reaktion des Gesteins auf Plattentektonik, Gebirgsmassive, aber auch menschliche Eingriffe z.B. Tunnel ode Bergwerke. Wenn der Spannungzustand die Festigkeit des Gesteins überschreitet, bricht das Gestein. Im Großen geschieht das bei Erdbeben, wobei sich angestaute Spannungen entladen. Im Kleinen kann es zu einer Rissbildung kommen, durch welche Wasser strömen kann - etwas was im Endlagerbereich vermieden werden soll.

Da es nur wenige direkte Daten über die Spannung gibt, wird das Spannungsfeld am Computer modelliert. Hier zeigen wir eine Möglichkeit das Spannungsfeld zu modellieren und gleichzeitig auch die modellieren und gleichzeitig auch die stellen. Allerdings sind deren Unsicherheiten sehr groß. Daher benutzen wir weitere Informationen aus Bohrlöchern und beobachtete Seismizität (Erdbeben, hier sehr kleine, kaum spürbare) um die Unsicherheiten im Modellergebnis zu verkleinern.

Damit lässt sich die Aussagekraft von Spannungsmodellen deutlich steigern. Durch die berechneten Unsicherheiten lässt sich der nötige Sicherheitsspielraum definieren.

Heterogeneous rock properties: No time for an exhaustive quantification of uncertainties
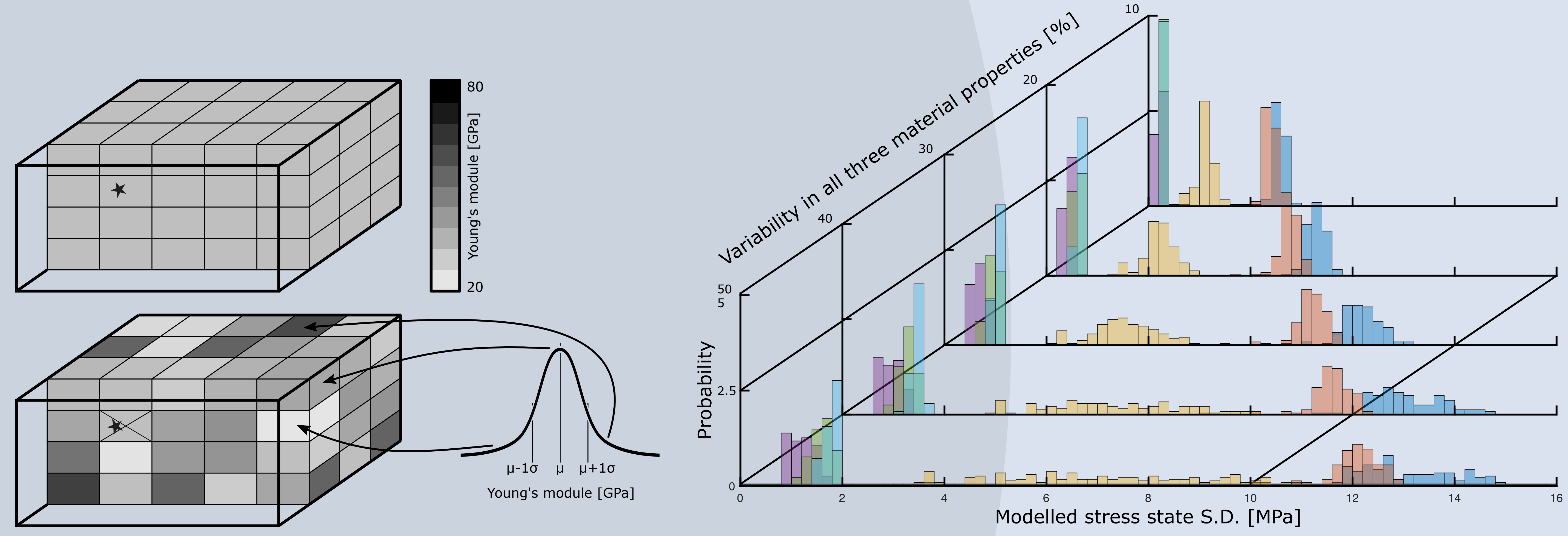

Modelled stress state S.D. [MPa]

A decisive factor for the manifestation of the stress state are the rock properties Young's module, Poisson ratio, and Density which are inherently heterogeneous to a variable degree. While a general range of rock properties may be known, the exact distribution is not known. Thus, the heterogeneity is reflected in the uncertainties in the stress state (see above).

Usually models assume a homogeneous distribution of rock properties throughout a lithological unit (Left top). In reality, heterogeneities to at least some degree have to be expected (Left bottom). Their influence on the uncertainties in the modelled stress state is indicated by the colour-coded standard deviations of the modelled stress states components ( $x$-axis) throughout the model volume and its variability ( $y$-axis) as a histogram (right) Different variabilities between $10 \%$ (back) and $50 \%$ (front) of all three rock properties are assumed.

These heterogeneities significantly increase the number of possible model scenarios. We propose to use a generic modelling to assess the additional uncertainties in each component of the stress tensor and add them to the uncertainties of the high resolution model. 